\title{
BARNA: Going for Gold
}

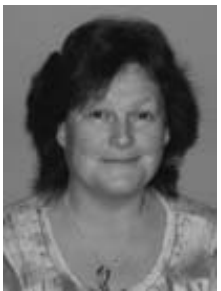

Manda Dunne

BARNA Chair

$\mathrm{T}$ There is always a lull after the Annual Conference. Well-earned holidays are taken, regrouping and reflecting high on the agenda. Having just watched more Olympic sport than I can recall, I was struck by how much I became involved. Sport is not really my thing and I must confess I have never really taken much interest in the Olympics. Maybe it is because we are the next host, I really don't know. It was impossible to not to be drawn into the sheer pride and excitement whenever a British participant won Gold, and didn't we do well!

Nevertheless, BARNA is my thing and I can equal my feelings to how I felt at the BARNA Conference in June of this year to the buzz of GB going for Gold! I was quite apprehensive as we had a new venue and a new format, and without a crystal ball, you never really know how things will work out.

Well, you all exceeded my expectations and made me feel proud and honoured to be your Chair. I can't tell you how good it was to see so many delegates attending. Boris Johnson even made an appearance as he passed through. There was a buzz of enthusiasm and excitement, equalled by a mass of smiling faces. I have to extend a huge thank you to each and every one of you who came on 6th June 2008 to make our day so successful. That includes you the delegates, speakers, exhibitors, our guests and everyone who came to help on the day. The support for the committee was fantastic which was very rewarding. A message came through at one point that there were not enough chairs in one of the rooms. Quickly some more were found but out of a negative always comes a positive. Not enough chairs, how wonderful, that must be good!

I am really looking forward to the BARNA Conference next year in Greenwich, and hope to see as many delegates there again. We cannot do this without you, so please remember we need you and your enthusiasm to support our passion so BARNA can truly 'Go for Gold!' 